\title{
Does teaching language automatically entail teaching culture?
}

\author{
Hawkar Akram Awla \\ Koya University, Faculty of Humanities \& Social Sciences, English Department, Koya, Kurdistan Region, Iraq
}

\section{Email address:}

hawkar.akram@koyauniversity.org

\section{To cite this article:}

Hawkar Akram Awla. Does Teaching Language Automatically Entail Teaching Culture? International Journal of Language and Linguistics. Vol. 2, No. 4, 2014, pp. 258-262. doi: 10.11648/j.ij11.20140204.13

\begin{abstract}
It is widely believed that understanding a language does not only entail knowledge of phonology, grammar and vocabulary, but it also requires one to have information about certain features of the culture of that language (Cakir, 2006). There are various views regarding the importance of culture in language teaching. The aim of this paper is to discuss whether teaching language automatically entails teaching culture or not. To answer this question, the relationship between language and culture is first examined by referring to various views in literature. Then, teaching language and culture is explained by drawing on different points of view. This study uses a theoretical approach to review relevant literature on the topic and present different arguments for and against teaching language and culture.
\end{abstract}

Keywords: Language, Culture, Teaching Language and Culture

\section{Introduction}

It is generally believed that language and culture are related in one way or another. Since culture (as defined by Sapir) refers to "what a society does and think", it can be said that language affects and is affected by how we think and behave (Cooper, 1973:100, cited in Al- Samarrai, 2007:2). Several researchers have been interested in studying the close relationship between language and culture (e.g. Howell and Vetter, 1976; Brown 1987; Buttjes, 1990; Kramsch, 1998; Tang, 1999; Judd, 1999; Jiang, 2000). Despite the close relationship between language and culture, some researchers discuss the possibility of separating the two (e.g. Pinker, 1994; Risager, 2007).That is, they believe that learning a language may not lead to learning the culture of the speakers of that language. There are different views on teaching language and teaching culture, which are mainly based on the arguments regarding the relationship between language and culture. Some researchers indicate that teaching language means teaching culture (e.g. Buttjes, 1990; Jiang, 2000; Peterson and Coltrane, 2003) while others have the opposing view (e.g. Kachru and Nelson, 1996; Tang, 1999; Seidlhofer, 2001; Sardi, 2002). This paper aims at researching arguments on teaching language and culture. The paper, excluding the introduction, is divided into three sections: in the first section the link between language and culture is explained. The second section deals with teaching language and culture. The last section is a conclusion which sums up the main points.

\section{The Link between Language and Culture}

The relationship between language and culture has attracted the attention of anthropologists, psychologists, sociologists, and linguists for many years. They have attempted to understand how cultural elements impact various aspects of human behavior such as language, perception, communication, and cognition (Gilmour, 2002).

Some researchers believe that language and culture are intimately connected, to the extent that language is often considered to be a part of culture (Buttjes, 1990; Kramsch, 1998; Brown, 1987; Tang, 1999; Jiang, 2000). Brown (1987:123) explains the relationship between the two as follows "a language is a part of a culture and a culture is a part of language; the two are intricately interwoven so that one cannot separate the two without losing the significance of either language or culture". According to Sapir-Whorf s' hypothesis, "language is not just an element of culture which interacts with many other elements, rather it is the source from which cultures emerge and take shape" 
(Cooper, 1973:99 as cited in Al- Samarrai, 2007:3). In a nut shell, language and culture are inextricable.

Due to the close tie between language and culture, different metaphors have been used to describe this relationship. Some people consider language as a mirror of culture through which one can see a culture within it. Another way of assimilating the two is by comparing them with an iceberg where the surface part denotes language and a small part of culture, while the part under the surface symbolizes the invisible side of culture. Language and culture have also been compared with living creatures; language is viewed as flesh and culture as blood. Language without culture is a dead body, and culture in the absence of language is without shape (Jiang, 2000:328).

Kasaian and Subbakrishna (2011:170) compare language and culture to Siamese or conjoined twins: "two people who are born with their bodies joined to each other whose separation may lead to the death of either or both of them". In my opinion, language and culture are inseparable as shadow and body. As a shadow cannot be detached from the body itself, also language cannot be disconnected from culture.

In Kramsch's (1998:3) words, culture expresses, embodies, and symbolizes cultural reality. Firstly, language expresses cultural reality: when people speak, they utter words which express ideas, facts, opinions, and events. These words are understandable by other people who use the language owing to the shared world of experiences and knowledge.

Secondly, language embodies cultural reality: members of a social group or community create experiences using language via various verbal and non-verbal means such as accent, tone of voice, facial expressions, gesture, and conversation style. They also create experiences by giving meaning to language through the way they opt to communicate, for example, reading a newspaper, composing an email, the way people answer the phone, which are culturally specific.

Thirdly, language symbolizes cultural reality: language includes a system of signs that is viewed as having a cultural significance. People identify themselves through their language use; they consider their language as a symbol of their social or ethnic identity. If the use of language is disallowed, it is seen as a denial of their culture and social group. Carbett (2003) indicates that learners employ language, to a certain extent, to maintain and construct group identity and to build social norms of attitude, values and beliefs. Specific linguistic choices are therefore filled with cultural values.

Furthermore, culture appears to have its own grammar which is reflected in language. A grammar of culture includes a number of rules for making patterns of behavior. Comparing an American and Japanese example makes this clearer. When an American sees a car coming, s/he almost always employs the present continuous (the car is coming), while Japanese utilize the present perfect (the car has come) (Howell and Vetter, 1976:374). Thus, judging by how the grammar of the culture speaks its own language, it seems obvious that culture and language are inextricably linked.

Tang (1999:1) makes the point that language is culture. When one attempts to learn a language, French, for instance, $\mathrm{s} /$ he is not only taking in the linguistic elements of that language but rather absorbing everything related to France and French; "that is beautiful, that is romantic, that is spoken along the Seine, and so on". This highlights the point that language and culture are interrelated. To use a language properly, one has to be capable of thinking in that language. So, if one thinks in a language, so that $\mathrm{s} / \mathrm{he}$ can speak that language, one might hold the belief that $\mathrm{s} / \mathrm{he}$ almost, in some way, has begun to have the identity of that language (Tang, 1999:1). For example, a bilingual person might regard him/herself as having two identities and cultures. Ylänkö (2013) examined the linguistic and cultural identities of three second-generation FinnishCanadian bilinguals who were born and brought up in Canada but moved to Finland as they grew up. Three semistructured interviews were used for the data collection. The results indicated that all the participants called themselves Finish-Canadian. One reason for using this term was that it revealed their identities. Although they were brought up in Canada, they also regarded Finland as a big part of their heritage. As far as cultural identity was concerned, all the participants considered themselves to be bicultural.

Buttjes (1990) discusses the reasons for the inseparability of language and culture in more detail by drawing on some ethnographic studies: 1) acquiring a language is not adhered to a universal order but rather it differs cross-culturally; 2) Being a proficient member of a social group requires one to understand various language exchanges in specific social situations; 3) every society arranges the way children take part in particular situations, and this influences the content, function and form of children's speech; 4) the caretakers' main concern is not with the knowledge of grammar but with way the sociocultural knowledge is transmitted; 5) a native learner not only acquire language but $\mathrm{s} / \mathrm{he}$ also acquires paralinguistic rules of his or her own culture.

Language and culture are also interwoven. Pragmatically, learners who acquire a second or foreign language, not only need linguistic accuracy, but they also have to master pragmatic and sociolinguistic rules and failure to do so leads to communication breakdown (Judd, 1999). For example, when a second language learner sees the phrase "Baby sale" on the window of a shop, due to her/his pragmatic competence, $\mathrm{s} /$ he realizes that the shop is not selling babies but has items on sale for babies (Brock and Nagasaka, 2005:19).

Despite these links between language and culture, some researchers argue the possibility of separating language and culture. In Pinker's (1994:19) view, "language is not a cultural construct, but the result of a long biological adaptation process- it is an instinct that is no more or less remarkable than the instincts which allow bats to navigate or migratory birds to fly home". Pinker appears to see 
language as a universal phenomenon.

Risager (2007) states that understanding the link between language and culture can be put between two opposite poles: on the one hand, it is feasible to view language as being intimately intertwined with culture; on the other hand, it can be regarded as a tool for communication that has no relationship to culture, for example, when English is considered as a lingua franca or international language. She sees none of these views as satisfactory. The first one is closely related to the notion of a closed universe of people, history, culture and language- an idea, which originated from the national-romantic current in Europe since 1980s. This idea is incompatible with the world of today distinguished by numerous types of transitional processes at various levels. The view that language is considered as a tool for communication that has no relationship to culture is related to a classical structuralist concept of viewing language as a system or autonomous structure. This notion is not convincing either, as it rejects "the cultural bearing and cultural-creating potential of human languages" (Risage, 2007:166).

Kasaian and Subbakrishna (2011) discuss the possibility of separating language and culture from three perspectives: sociological, psychological and system-oriented. From a sociological point of view it is plausible to view language as separable from its first language context. For instance, "when learners of English learn or acquire English as a second language and use it in contexts which are different from its first language context, English is used out of its original context and is a proof of separability" (Kasaian and Subbakrishna, 2011: 172). The authors give an example of the Nigerian writer Chinua Achebe (1975) who asked this question "Can English carry the weight of my African Experience?" in essence, he was making reference to the separability of language and culture from a sociological point of view and demonstrated that this separation is plausible by writing in English, in lieu of opting to express his African experience in his mother tongue. From a psychological perspective, Kasaian and Subbakrishna (2011) make the point that inseparability of language and culture makes sense when someone speaks the language as a first or early second language, but how can we talk about the inseparability of English and western culture when English is taught as a second or foreign language? The researchers believe that "For a language learner whose life context has little or no link with the cultural context within which English is said to be embedded, the assumption of inseparability of the English language from its western cultural context is absurd" (Kasaian and Subbakrishna, 2011:173). From a system- oriented perspective, they indicate that the inseparability of language and culture is fallacious "for a language like English which has transcended the defined geographical limits of nations, areas and communities that originally hosted this language and can no longer be associated with the cultural communities in one single area" (Kasaian and Subbakrishna, 2011:173).
Vahdani (2005:97) points out that in Iran people "tend to have some defensive inhibition in learning English with their culture" due to their concern about western cultural invasion. Therefore, learning materials such as books, videos, tapes and films are deliberately censored in order to take out the ones which are not in accordance with the cultural values and norms of Iranian society. Vahdani indicates that they do so this, partially, to prevent culture shock. He affirms that culture shock is regarded as a natural instinct in a second language (SL) context, but is found to be counterproductive in a foreign language (FL) setting like Iran. Thus, he cautiously says that "FL acquisition does not necessarily involve acculturation process" (Vahdani, 2005:.98). In my view, language and culture are inseparable. Despite indications for separating the two, they do seem to be problematic.

\section{Teaching Language and Culture}

The arguments for teaching language and culture together are based on the arguments of the relationship between language and culture (Risager, 2006). There are different views regarding whether or not teaching language entails teaching culture. The researchers who advocate the existence of a close link between language and culture indicate that teaching language automatically entails teaching culture (Brown, 1987; Buttjes, 1990; Jiang, 2000; Gao, 2006). On the other hand, the opponents of this view (Kachru and Nelson, 1996; Tang, 1999; Seidlhofer, 2001; Sardi, 2002; Dlaska, 2000) state that teaching language appears to be different from teaching culture. In other words, they say that language and culture seem to be separate entities, therefore they should be taught independently. In the following sections some different views are presented.

Since language and culture are inextricable, language pedagogy means culture pedagogy. Buttjes (1990:55) justifies this view as follows: 1) it is impossible to teach language codes separately, as sociocultural transmission processes are likely to operate on various levels, for instance, the cultural context of textbooks, the content of language exercises, and the attitudes of teachers towards the particular culture; 2) when teachers play the role of secondary caretakers, they not only need to monitor the linguistic production of their students, but they should also be aware of the complicated and various processes of intercultural mediation that any FL learner goes through. To stress that foreign language (FL) pedagogy entails foreign culture pedagogy, Brown (1987:33), focuses on "acculturation" - the process of adjusting to a new culture.

It is assumed that children acquire their mother tongue along with cultural knowledge (Brooker and Woodhead, 2010). This premise may lead us to the belief that neither the first nor the second language can be learned independently of their culture (Sardi, 2002). It is, therefore, almost infeasible to teach a particular language, unaccompanied by its particular culture (Jiang, 2000). 
Anthropologists and linguists have acknowledged that the use and form of a language is the reflection of its cultural values of the community in which the language is used. Therefore, linguistic competence alone is inadequate for language learners in order to successfully master the language. They have to be familiar with culturally appropriate ways of, for instance, greeting people, expressing gratitude, addressing people, and agreeing or disagreeing with somebody. They should realize that some behaviors may be appropriate in their culture but may be inappropriate in another community of a particular language (Peterson and Coltrane, 2003). For example in Chinese, if you ask somebody "where are you going" it is simply a greeting, while in English if this sentence is used in the sense of a greeting, it may end up irritating the other person (Gao, 2006). Similarly, a popular way to greet someone in Chinese is to say (...phonetically using pinyin) "chr bao^ le ma?" which is translated into English as "Have you eaten?" or "Are you full?" This greeting originated from the ancient Chinese culture as there was an extended period of famine. In China, it is culturally important to question somebody upon meeting, whether or not they have eaten. This indicates consideration and care for the other person. However, if you greet a westerner with this, they think you are insane, or that it is not your business. Therefore, one should not only compare, but contrast the cultural discrepancies in language usage (Leveridge, 2008)

Tang (1999) indicates that it might be possible to separate language and culture based on the arguments of Gardner and Lambert (1972) and Brown (1994), namely through an integrative motivation and an instrumental motivation. The former refers to the learners' inclination to acquire a language while engaging in a target culture. The latter refers to learners needing to learn a language in order to obtain a job or position in an institution (Tang, 1999). The argument is that the learners with an instrumental motivation are neither interested in the target language culture nor concerned with sharing their experience with native speakers. Thus, according to this argument teachers are assumed to have some kind of choice in integrating culture into their syllabuses. However, Tang insists that language and culture are closely linked; therefore, teaching language without teaching culture is pointless.

Dlaska (2000) points out that one of the reasons that makes teachers hesitant to include culture as a core subject of language teaching may be due to teachers' fear that the linguistic progress of the learners may be affected by integrating language study with such a heavy subject matter Dlaska, however, argues for an integrative approach towards language and culture as this provides motivation and coherence that a number of irrelevant topics usually do not allow for.

There are four viewpoints in regard to the integration or separation of language and culture teaching. The first one concerns the teaching of target language (TL) culture together with English so that learners can have the opportunity to acculturate into the culture where English is spoken ( Byram and Flemming, 1998). The second opinion is related to the separation of the TL culture and English where English is seen as an institutionalized variety (Kachru and Nelson, 1996). The other two positions also disagree with the notion of teaching English or a second language in general together with TL culture. Nonetheless, one of the positions advocates instructing the language learners' culture with English (Mckay, 2003; Kramsch and Sullivan, 1996). The final view takes the position that English has become an international language, therefore, it should be taught without cultural instruction (Seidlhofer, 2001).

Sardi (2002) states that it appears that there are some problems with viewing teaching language and culture as inseparable. Firstly, using target culture elements in English language teaching (ELT) processes supports the view of equating English with the way it is employed by native speakers. This opinion leads to the presumption that native speakers do not only represent, but also own the language. Secondly, choosing an appropriate culture to teach might be problematic especially in foreign language contexts where it appears impossible to concentrate on all cultures. Thirdly, some ELT course materials place emphasis on the target culture which may have an alienating effect on students who do not acculturate, and as a result, quit language learning.

As far as I am concerned, when someone learns a language, s/he, to some extent, picks up the cultural aspects of that language. As a Kurdish learner of English, I used to be recommended by teachers to think in English not in my mother language while speaking or writing. That is, they advised me not to translate word by word from Kurdish to English but rather try to find the equivalent in English. For example, a Kurdish learner of English may express "I am not in a good mood" as something like "I do not have a good weather" since this expression is used in Kurdish to indicate the state of your mood which seems meaningless for an English native speaker. Thus, teachers should not only teach language but rather incorporate the cultural aspects of the language as well.

\section{Conclusion}

The paper outlined an overview on the relationship between language and culture. Firstly, the concept of culture was explained. Then different views on the link between language and culture were examined. Afterwards a specific consideration was given to teaching language and culture by examining varied views in literature. It was concluded that language and culture are closely linked to the extent that language is considered to be culture and culture is regarded as language. Culture appears to have its own grammar which is reflected in language. A grammar of culture includes a number of rules for making patterns of behavior. When one attempts to learn a language $s /$ he is not only taking in the linguistic elements of that language but rather absorbing everything related to that culture. Language and culture are pragmatically interrelated. Learners who acquire a second or foreign language do not 
only need linguistic accuracy but they also have to master pragmatic and sociolinguistic rules. However, there are claims about separability of language and culture, but those who talk about the possibility of separating the two appear to be very cautious and at the same time discuss the inseparability of language and culture. Due to this close link between the two, it is suggested that teaching language, automatically entails teaching culture. It is also suggested that teachers should not only teach language but rather include the cultural aspects of the language as well.

\section{References}

[1] Al- Samarrai, N. (2007). Language and Culture A Philosophical Hypothesis. Tikrit University Journal for Humanities, 14 (4), 1-14. Retrieved online on July, 3, 2014 from http://www.iasj.net/iasj?func=fulltext\&aId=44474

[2] Brown, H. D. (1994). Principles of Language Learning and Teaching. Englewood Cliffs, New Jersey: Prentice Hall Regents.

[3] Brown, D. H. (1987). Principles of language learning and teaching $\left(2^{\text {nd }}\right.$. Ed.). New Jersey: Prentice-Hall, Inc.

[4] Brock, M.N, Nagasaka, Y. (2005). Teaching pragmatics in the EFL classroom? SURE you can! TESL Reporter, 38 (1), $17-26$.

[5] Brooker, L. \& Woodhead, M. Eds. (2010). Culture and Learning: Early Childhood in Focus, 6. Milton Keynes, UK: The Open University.

[6] Buttjes, D. (1990). Teaching foreign language and culture: Social impact and political significance. Language Learning Journal, 2, 53-57.

[7] Byram, M. \& Flemming, M. (1998). Language Learning from an Intercultural Perspective. (Eds.).Cambridge: Cambridge University Press.

[8] Cakir, I. (2006). Developing cultural awareness in foreign language teaching. Turkish Online Journal of Distance Education-TOJFE, 7(3), 154-161.

[9] Corbett, J. (2003). An intercultural approach to English language teaching. Clevedon: Multilingual Matters.

[10] Dlaska, A. (2000). Integrating culture and language learning in institution-wide language programmes. Language, Culture and Curriculum, 13(3), 247-263.

[11] Gao, F. (2006). Language is culture- on international communication. Journal of Language and Linguistics, 5(1), $58-66$.

[12] Gardner, R. C., \& Lambert. W. (1972). Attitudes and Motivation in Second Language Learning. Rowley, Massachusetts: Newbury House.

[13] Gilmour, E. C. (2002). Language, culture and learning. The Journal of Miyagi Gakun University, 95, 1-19. Retrieved online on May, 7, 2012, from http://web.me.com/elainecglmr/Socioculture/sociocultural_1 earning_files/Culture $\% 20 \mathrm{in} \% 20$ Second $\% 20$ language $\% 20 \mathrm{Te}$ aching $\% 20$ and $\% 20$ learning.pdf.
[14] Howell, W. R. \& Vetter, J. H (1976). Language in behavior. New York: Human Sciences Press.

[15] Jiang, W. (2000). The relationship between culture and language. ELT Journal, 54(4), 328- 334.

[16] Judd, E. L. (1999). Some Issues in the Teaching of Pragmatic Competence. In E. Hinkel,ed., Culture in second language teaching and learning. Cambridge: Cambridge University Press, 152-166.

[17] Kachru, B. B. \& Nelson C. L. (1996). World Englishes. In S. L. McKay and N. H. Hornberger (Eds.), Sociolinguistics and language teaching (pp.71-102). Cambridge: Cambridge University Press.

[18] Kasaian, S.A. \& Subbakrishna, R. (2011). Standard English as a 'Fiat Code' and the Dwindling Faith behind It. Language in India, 11(3), 163-177.

[19] Kramsch, C. (1998). Language and culture. Oxford, UK: Oxford University Press.

[20] Kramsch, C. \& Sullivan P. (1996). Appropriate pedagogy. ELT Journal 50/3: 199-212.

[21] Leveridge, A. N. (2008). The Relationship Between Language \& Culture and the Implications for Language Teaching. Sitemap. TEFL. Net. Retrieved online on June 28, 2014, from http://edition.tefl.net/articles/teachertechnique/language-culture/

[22] McKay, S. (2003). Teaching English as an international language: The Chilean context. ELT Journal 57/2: 139-48.

[23] Peterson, E. \& Coltrane, B. (2003). Culture in Second Language Teaching. ERIC Digest. Retrieved online on May 18, 2012, from http://www.cal.org/resources/digest/0309peterson.html.

[24] Pinker, S. (1994). The language instinct. New York: Morrow.

[25] Risager, K. (2006). Language and culture pedagogy. Clevedon: Multilingual Matters.

[26] Risager, K. (2007). Language and culture pedagogy. From a national to a transnational paradigm. Clevedon: Multilingual Matters.

[27] Sardi, C. (2002). On the relationship between culture and ELT. Kalbu Studijos/Studies about Languages, 3, 101-107.

[28] Seidlhofer, B. (2001). Closing a conceptual gap: the case for a description of English as a lingua franca. International Journal of Applied Linguistics 11(2), 133-58.

[29] Tang, R. (1999). The place of "culture" in the foreign language classroom: A reflection. The Internet TESL Journal, 5(8), 1-2.

[30] Vahdani, F. (2005). Culture And Language Teaching. Retrieved on July, 7, 2014, from http:/www.sid.ir/en/ViewPaper.asp?ID=197826\&varStr=3.1 4159265358979;VAHDANI\%20F.;PEYKE\%20NOOR\%20J OURNAL;SUMMER\%202005;3;2\%20(LEARNING\%20A ND\%20DISTANT\%20EDUCATION);101;106

[31] Ylänkö, M. (2013).Bilingual identity: Finnish-Canadians' linguistic and cultural identities and changes in them. BA thesis, University of Jyväskylä, Finland. Retrieved online on July, 10, 2014, from https://jyx.jyu.fi/dspace/bitstream/handle/123456789/41770/ URN_NBN_fi_jyu-201306141971.pdf?sequence $=5$. 